\title{
Implementation of Gamification to Improve Learning in Museum
}

\author{
Kelvin Kristianto, Kerin Dela, Handri Santoso \\ Human Computer Interaction, Surya University, \\ Jl. M.H. Thamrin KM 2.7 Panunggangan Utara, Pinang, Tangerang, Banten, Indonesia
}

\begin{abstract}
The traditional role of museum is to collect objects and materials of cultural, religious and historical importance, preserve them, research into them and present them to the public for the purpose of education and enjoyment. However, people have started to avoid going there since the atmosphere offered there is monotonous and people would rather choose to easily search for the wanted information through their mobile device. So, in order to raise people's motivation and effectiveness in learning through museum, gamification method could be implemented in museum visits. Gamification refers to the use of game elements and gamedesign techniques in non-game contexts. Through this research, a gamification system with QR Code technology approach will be created. In order to achieve the system's goal, Spiral Model is used to develop the application. While to evaluate the learning aspect, two out of four levels of Kirkpatrick model will be used which are reaction and learning.
\end{abstract}

Key words: Gamification, Learning in Museum, Spiral Model, Kirkpatrick Model

\section{INTRODUCTION}

The traditional role of museum is to collect objects and materials of cultural, religious and historical importance, preserve them, research into them and present them to the public for the purpose of education and enjoyment. In term of education, museum has its fundamental objective which is to educate, and it is only the museum that has the capacity and the ability to enrich the educational process by exposing the public especially children to their history in a positive way [1]. However, these past years, debasement of $50 \%$ in the number of museum visitors can be seen [2]. In addition, due to the rapid growth of technology, people would think twice before going to museum to just learn things that they could easily search through the internet especially with the monotonous experience offered by the museum.

A research in the US and UK shows that people does not choose to visit a museum based on its collection, but it is the environment and the whole interaction visitors could experience throughout the museum that matters, where entertainment and education merged. With this information in hand, it is possible that in order to improve learning in museums is by creating an interactive experience through gamification implementation in museum visits [3]. Gamification itself is the use of game elements and game-design techniques in non-game contexts which in this case, the non-game contexts refers to museum visits [4]. In order to gain an optimum result out of the gamification implementation, there are three elements to complete, which are "Dynamics", "Mechanics" and "Components" [5].

Gamification implementation in various contexts has been proven to be an effective method to motivate people to do things which they got no desire to do [6]. As the testing team in Microsoft done so by creating a testing game which the employees will be awarded points for each error they manage to detect and ranked on a leaderboard. Such method created a competitive dynamic for the participating employees and made them willingly do what they previously have no desire to do [5]. Therefore, the aim of this study is to improve learning in museum visitations by gamification implementation which will be presented in form of a trivia android application named "Museum Adventure" with the learning aspect being evaluated using the "Kirkpatrick model".

Corresponding Author: Kelvin Kristianto, Surya University, J1. M.H. Thamrin KM 2.7 Panunggangan Utara, +6289651364759 
Kirkpatrick model is widely known as Kirkpatrick four levels evaluation model was first founded by Dr. Don Kirkpatrick. The model was called so since it contains four levels which are: Level 1 Reaction, Level 2 - Learning, Level 3 - Behavior and Level 4 - Result [7]. However, in this study only the first two levels were being used.

There are four aspects that are needed to develop an effective gamification system in term of education. The first aspect is goal settings, which is the main goal the system wants to achieve. Next one is the player engagement, which is giving the gamification itself a characteristic personalization. Besides that, gamification needs to have a progressive design, where challenge and complexity should evolve along the way of the system. Lastly, gamification should let social interactions to happen between users which is called the environment building aspect [8].

\section{EXPERIMENT}

\section{Modeling}

In developing the application "Museum Adventure", spiral system development life cycle (SDLC) is being used where here are four stages in each cycle which will be done repeatedly until the application reach its objective. The four stages are [9]:

1. Determine objective

2. Identify and resolve risk

3. Development and test

4. Plan the next iteration

\section{First Cycle}

\section{Determine Objective}

Since the objective of this application is to improve learning in museum visitations, several gamification components were chosen through a user survey in order to get an accurate result on what the users thought as the best gamification components which could boost their motivation in learning.

Besides that, the data was also collected using the Kirkpatrick model which are "Reaction" and "Learning". In the "Reaction" level, respondents were asked questions regarding their satisfaction towards the whole learning process. While in the "Learning" level respondents were asked questions related to the targeted museum's artefacts.

The respondents were divided into two groups which are group of people who haven't visited any museum in 6 months [10], and group of people who had just visit the targeted museum. The data obtained from this stage will then be used as the development base of the application.

\section{Identify and Resolve Risk}

After obtaining the main gamification elements which are "quest" and "achievement" from the previous stage, those elements are going to be analyzed deeper using the spiral method and gamification development by Werbach which can be seen in the table below.

Table 1. Spiral model analysis with gamification first

\begin{tabular}{|l|l|}
\hline Main Objective & $\begin{array}{l}\text { To improve learning in } \\
\text { museum visitation }\end{array}$ \\
\hline Target & Museum visitors \\
\hline Target Behavior & $\begin{array}{l}\text { To read the museum } \\
\text { artefacts' annotation } \\
\text { thoroughly }\end{array}$ \\
\hline Activity Cycle & $\begin{array}{l}\text { Completing the quest and } \\
\text { reach achievement }\end{array}$ \\
\hline Motivation & Gain rewards \\
\hline FUN Factor & $\begin{array}{l}\text { Learning new things } \\
\text { through new method }\end{array}$ \\
\hline
\end{tabular}

Based on the analysis from the table above, mainly from the activity cycle of this application, the mechanics which will be used to motivate people to use this application are "Rewards" and "Challenges". At last the dynamics, the main objective which this application will achieve is "Emotion", this application aim to reach the user's curiosity and motivate them to gain information from the museum.

The application itself makes user learn through their museum visitations by giving them questions based on the museum artefacts around them. Users should go around the museum to search for the answers which is the quest gamification aspect this application would like to achieve. Besides the main adventure, to achieve the achievement gamification aspect, there are several challenges the users could complete. While the user go around the museum to search for answers, they could input their answers by scanning the QR Code spread along the museum artefacts. When a session has been done, users will receive points where it is then could be exchanged with rewards.

\section{Development and Test}

In this stage, the application is being developed based on the requirements gained from the previous stages. Since one of the requirement is to reach the user's curiosity, QR Code was selected as one of the tool in this system, since it is commonly used in Asia because it could trigger users to find out what's inside it and scan it using their device. [11].

After reviewing the requirements, a system was then designed as shown in the flowchart below. 


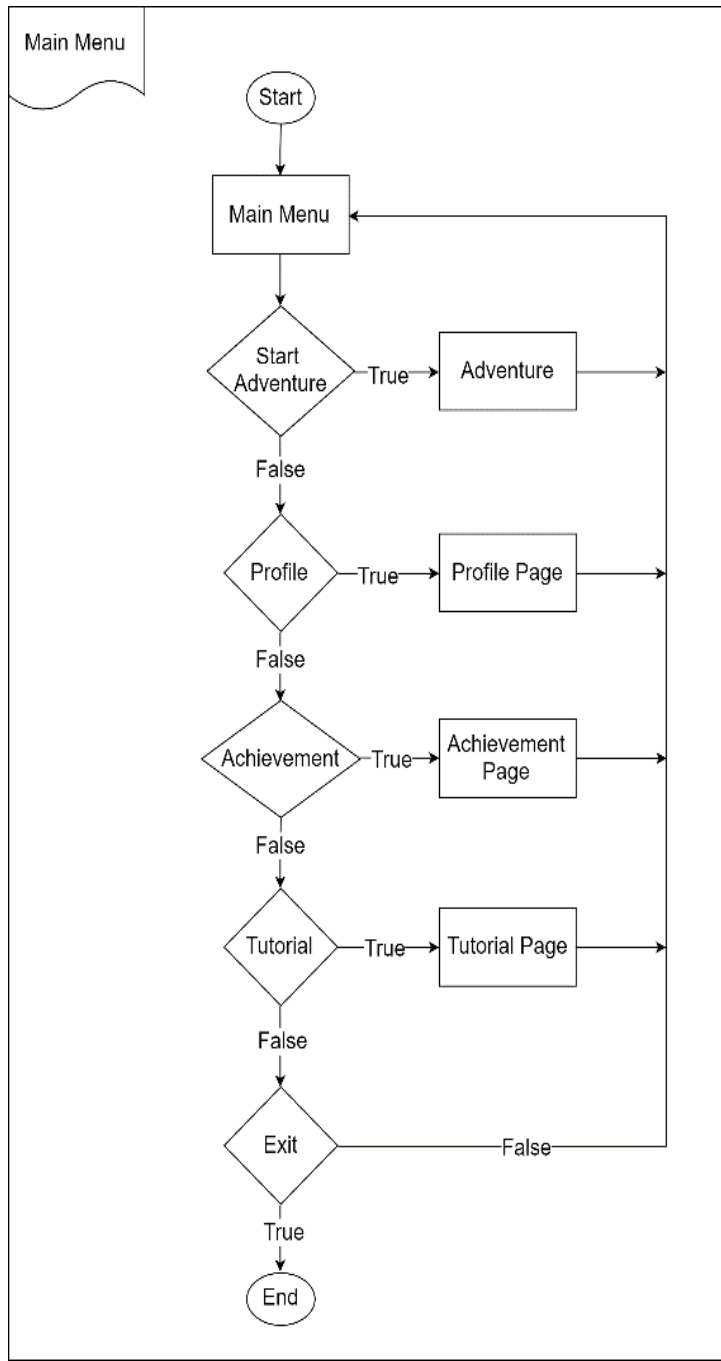

Figure 1. Main Menu Flowchart First Cycle

In this step, the application has been made in form of a prototype which is then being tested internally in PP-IPTEK Museum TMII, Indonesia. Based on the test result, this prototype needed some changes in the system flow for it to be more public friendly.

The problem users encounter during the testing were how the smartphone energy drained because of the application and cause the users to forcefully quit from the application. Due to that problem, users should rescan the museum code and are not able to continue the game from where they left.

\section{Plan the Next Iteration}

Errors and feedbacks from the testing stage will then be done in the next iteration.

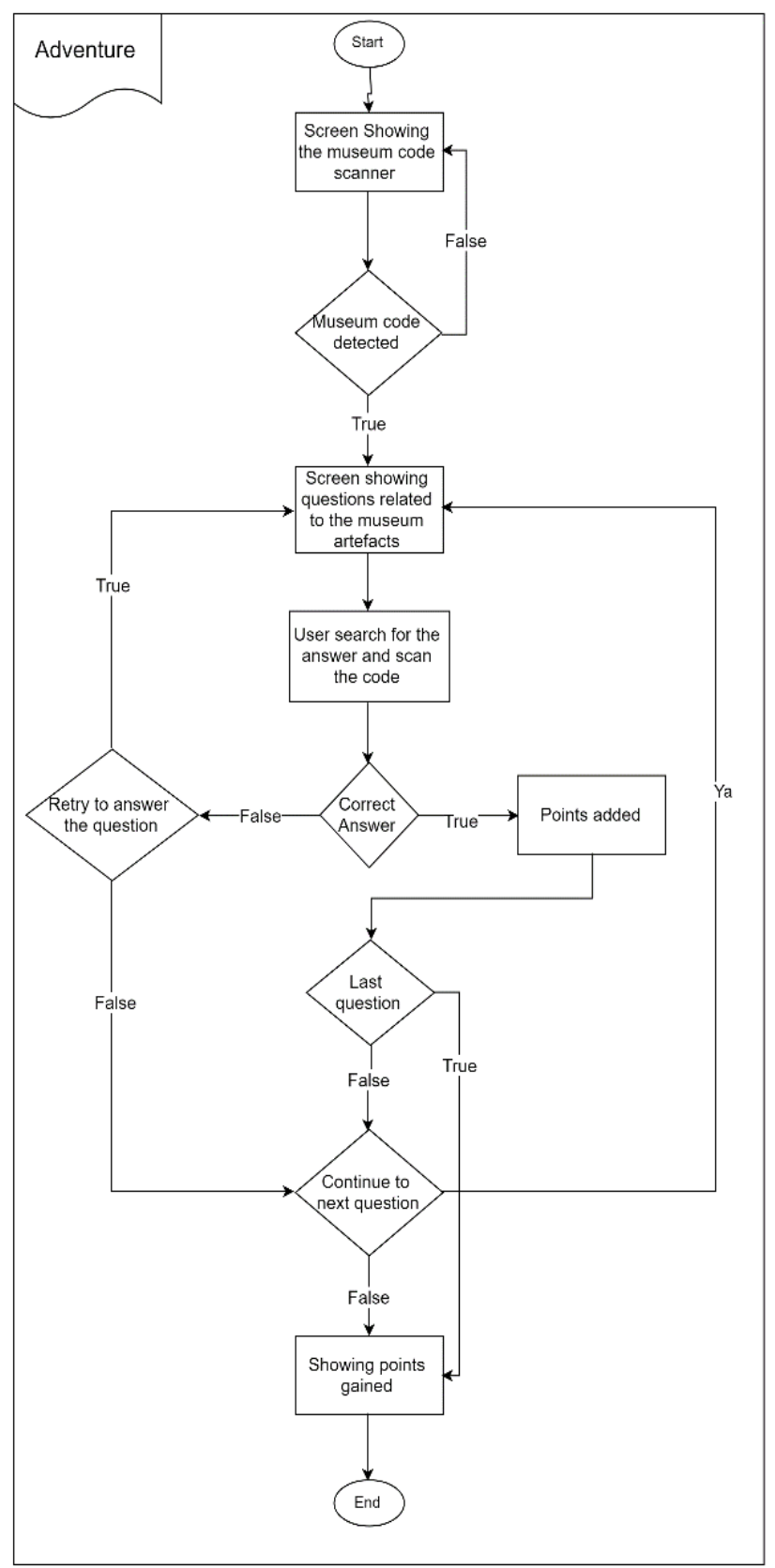

Figure 1. Adventure Flowchart First Cycle.

\section{Second Cycle}

\section{Determine Objective}

In this iteration process, this application still aim for the same main objective which is to improve learning in 
museum visitations, however, after gaining results from the previous iteration process, some changes and upgrades are needed for this application to reach the main objective according to the users' requirement. Those changes are to make the system easier for the user, and to prevent user from rescanning the museum code after quitting the application.

\section{Identify and Resolve Risk}

Based on the objective of this second iteration as mentioned before, below is the table showing the analysis on how to solve problems from the previous iteration.

Table 2. Spiral model analysis with gamification second cycle

\begin{tabular}{|l|c|}
\hline Main Objective & $\begin{array}{l}\text { Fix problems from the } \\
\text { previous iteration }\end{array}$ \\
\hline Target & $\begin{array}{l}\text { Does not change the main } \\
\text { function of the application }\end{array}$ \\
\hline Risk/ Problems & \begin{tabular}{l} 
Difficulties in \\
finding the answer \\
due to the wide \\
museum area \\
The adventure \\
restarts from the \\
beginning, and \\
rescanning the \\
museum code is \\
needed after \\
quitting the \\
application. \\
\hline Solution
\end{tabular} \mid $\begin{array}{l}\text { Additional feature: } \\
\text { Clue about the } \\
\text { answer's location } \\
\text { Additional system } \\
\text { path: List of } \\
\text { visited museums } \\
\text { are given }\end{array}$ \\
\hline
\end{tabular}

\section{Development and Test}

The application and the system are then being upgraded according to the analysis on the previous process. The new system is shown on the below flowchart.

After the system was done, it was tested in PPIPTEK Museum TMII, Indonesia. The visitors were asked to use the application during their visit and then answer several questions related to the museum artefacts. Besides getting to know how the user improve in learning using the application, feedbacks on what could make the application better were also received

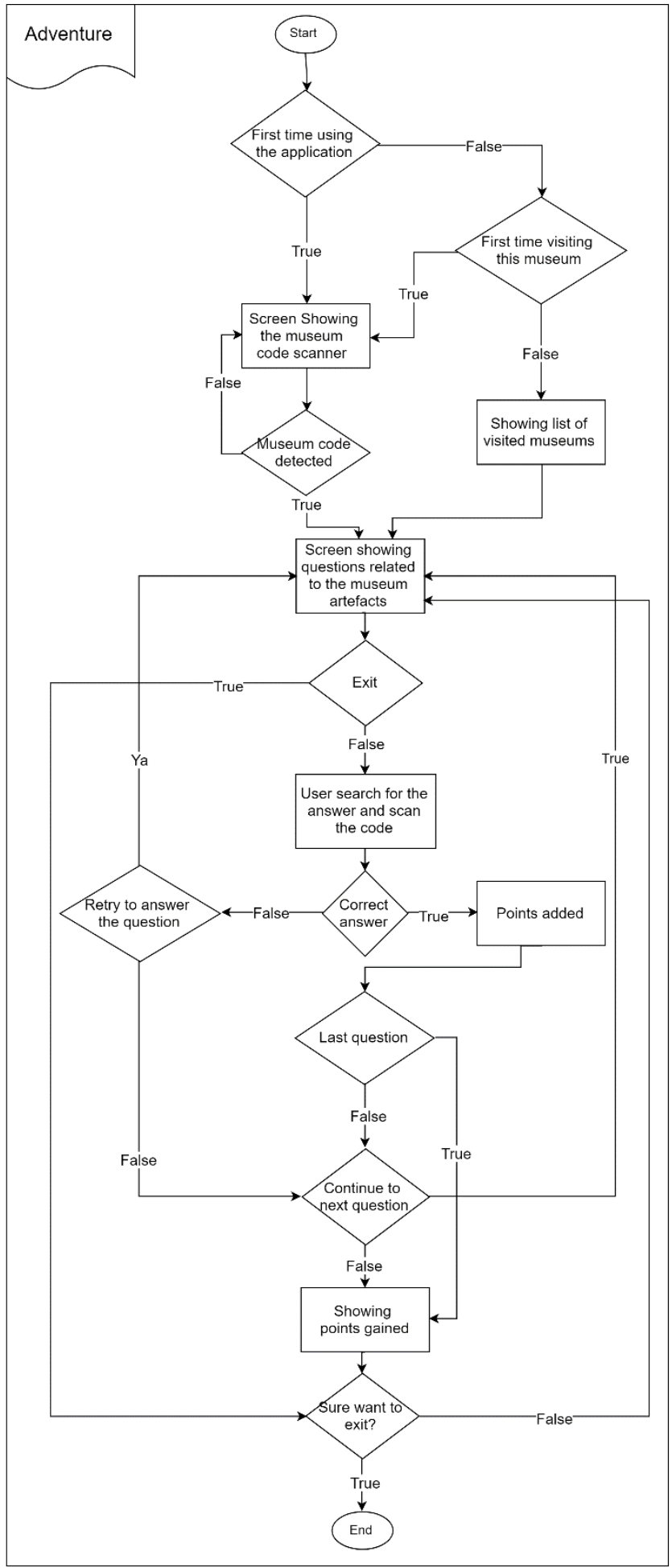

Figure 3. Adventure Flowchart Second Cycle

\section{Plan the Next Iteration}

Errors and feedbacks from the testing stage will then be done in the next iteration. 


\section{CALCULATION}

These three groups used to determine the significant of gamification in learning at the museum. The Score from testing result will be analyzed by using analysis of variance (ANOVA) One-Way. ANOVA is a statistical method to test the significant of mean differences among three or more treatment conditions [12]. This research using three groups with three different treatment. Which is group 1, the one who were not going to museum for more than six month. Group 2, the one who currently visiting the museum. Group 3, the one who used Museum Adventure application when visiting museum.

ANOVA was conducted to compare effect of gamification on the score result of a test of visitor in museum.

$$
\mathrm{F}=\frac{\text { variance beetween treatment }}{\text { variance within treatment }}
$$

Value obtained from the $\mathrm{F}$ test shows how effective was the gamification implementation on a system. If $\mathrm{F}$ test value $>\mathrm{F}$ table 0.05 , then the gamification has significant impact on learning in museums.

\section{RESULT AND DISCUSSION}

There are three groups with different learning methods which its score will be discussed. The score results of the learning test from three groups can be seen in the table below,

Table 2. Score of three groups with different learning methods

\begin{tabular}{|c|c|c|c|}
\hline $\mathrm{R}$ & G1 & G2 & G3 \\
\hline 1 & 80.00 & 26.67 & 46.67 \\
\hline 2 & 53.33 & 40.00 & 86.67 \\
\hline 3 & 66.67 & 40.00 & 66.67 \\
\hline 4 & 53.33 & 40.00 & 73.33 \\
\hline 5 & 60.00 & 66.67 & 80.00 \\
\hline 6 & 60.00 & 33.33 & 66.67 \\
\hline 7 & 53.33 & 53.33 & 86.67 \\
\hline 8 & 60.00 & 40.00 & 93.33 \\
\hline 9 & 53.33 & 46.67 & 93.33 \\
\hline 10 & 86.67 & 60.00 & 93.33 \\
\hline 11 & 46.67 & 46.67 & 73.33 \\
\hline 12 & 46.67 & 60.00 & 93.33 \\
\hline 13 & 46.67 & 60.00 & 66.67 \\
\hline 14 & 66.67 & 46.67 & 73.33 \\
\hline 15 & 53.33 & 40.00 & 66.67 \\
\hline 16 & 60.00 & 60.00 & 60.00 \\
\hline 17 & 40.00 & 53.33 & 93.33 \\
\hline 18 & 73.33 & 60.00 & 86.67 \\
\hline 19 & 46.67 & 40.00 & 60.00 \\
\hline 20 & 40.00 & 40.00 & 60.00 \\
\hline 21 & 60.00 & 46.67 & 73.33 \\
\hline 22 & 73.33 & 40.00 & 80.00 \\
\hline 23 & 60.00 & 46.67 & 53.33 \\
\hline
\end{tabular}

\begin{tabular}{|l|l|l|l|}
\hline 24 & 73.33 & 40.00 & 53.33 \\
\hline 25 & 53.33 & 60.00 & 33.33 \\
\hline 26 & 60.00 & 60.00 & 60.00 \\
\hline 27 & 66.67 & 60.00 & 73.33 \\
\hline 28 & 73.33 & 60.00 & 33.33 \\
\hline 29 & 46.67 & 53.33 & 73.33 \\
\hline 30 & 46.67 & 40.00 & 66.67 \\
\hline 31 & 40.00 & 40.00 & 80.00 \\
\hline 32 & 40.00 & 40.00 & 73.33 \\
\hline
\end{tabular}

From the data above, ANOVA was conducted to compare between three groups. The result as shown in the table below,

Table 3. Comparison between three groups

\begin{tabular}{|c|c|c|c|c|c|}
\hline \multicolumn{6}{|c|}{ ANOVA } \\
\hline & $\begin{array}{l}\text { Sum of } \\
\text { Square }\end{array}$ & $\mathrm{df}$ & $\begin{array}{l}\text { Mean } \\
\text { Square }\end{array}$ & $\mathrm{F}$ & Sig \\
\hline $\begin{array}{c}\text { Between } \\
\text { Groups }\end{array}$ & 8495.370 & 2 & 4247.685 & 24.677 & .000 \\
\hline $\begin{array}{l}\text { Within } \\
\text { Groups }\end{array}$ & 160008.333 & 93 & 172.133 & & \\
\hline Total & 24503.704 & 97 & & & \\
\hline
\end{tabular}

From the table, there was a significant result between three group at $\mathrm{p}<.05$ level for three condition $[\mathrm{F}(2,93)=24.677, \mathrm{p}=0.000]$. Because the result statistically significant, compute for post hoc test are needed. This test is designed to compare each of our group to other every group are exist in this research. The selected test for this research is Tukey post hoc test. This test will compare group 1 and group 2, it will also compare group 1 and group 3 , it will also compare group 2 and group 3.

The post hoc comparison using Tukey HSD test indicated that the mean score for group $3(\mathrm{M}=71.04$, $\mathrm{SD}=16.21)$ was significantly different than the group 1 $(\mathrm{M}=57.50, \mathrm{SD}=12.30)$ and also group $2(\mathrm{M}=48.12$, $\mathrm{SD}=10.12$ ).

Taken together, these result suggest that gamification could improve learning in museum. By using gamification application visitor could learn by follow the flow of the museum instead of randomly visit the collection in the museum. The result gained shows that group one has greater score than group two which does not correspond to the expected result. That is why in the upcoming study, this aspect could be considered.

\section{CONCLUSION}

Museums are not just places to preserve historical artefacts, in fact it is a great learning place. However, even if it is a great place to learn new things, people prefer to not waste their time and just search for information through their mobile devices. To solve this 
problem, we decided to implement gamification through mobile application in museum visitation to improve learning in museums. Through this study, there are several points that we conclude:

1. Gamification could improve learning in museum since it motivates people using the components it has such as "Quest" and "Achievement" which are being used in this study also "Rewards" and "Challenges" as its mechanics to target the user emotion which is their curiosity. This could be the basis of how people should develop gamification and implements it in education.

2. Gamification also improve learning in museums by giving the visitors a clear direction on what to learn during their visit.

3. Gamification could improve learning in general and not limited to only improve learning in museums.

\section{REFERENCES}

[1] Arinze, E. (1999). The Role of the Museum in Society. Guyana: Guyana Workshop.

[2] Hari, L. (2011). Museum Gajah Sepi Pengunjung. From Kompas: http://nasional.kompas.com/read/2011/09/06/22411 98/museum.gajah.sepi.pengunjung

[3] WALTL, C. (2006). Museums for visitors: Audience development - A crucial role for successful museum management strategies. INTERCOM 2006 Conference Paper.
[4] Deterding,S., Dixon,D., Khaled,R. \& Nackle,L. (2011). From Game Design Elements to Gamefulness: Defining "Gamification". International Academic MindTrek Conference: Envisioning Future Media Environments. New York: ACM.

[5] Werbach, K., \& Dan, H. (2012). How Game Thinking Can Revolutionize Your Business For The Win. In K. Werbach, \& H. Dan, How Game jThinking Can Revolutionize Your Business For The Win. Philadelphia: Wharton.

[6] Burke, B. (2014). Gamify : How Gamification Motivates People To Do Extraordinary Things. bibliomotion.

[7] Widoyoko, E. P. (2009). Evaluasi program pembelajaran.

[8] Tu, C.-H., E., L., Montes, S., \& Yen, C.-J. (2015). Gamifi cation for Learning. In R. Papa, Media Rich Instruction Connecting Curriculum To All Learners (p. 203). New York: Springer.

[9] Boehm, B. (1988). A Spiral Model of Software Development and Enhancement. TRW Defense Systems Group.

[10] Ryan, C., \& Hsu, S.-Y. (2011). Why do Visitor Go to Museum? The Case of 921 Earthquake Museum, Wufong, Taichung. Asia Pacific Journal of Tourism Research.

[11] Soon, T. J. (2008). QR code. Synthesis Journal, 5978.

[12] Gravetter, F. J., \& Wallnan, L. B. (2012). Statistic for the Behavioral Sciences. Wadsworth: Cengage Learning 